\title{
Bibliometric analysis of research relating to radiation-induced lung injury [2001-2020]
}

\author{
Dandan Wang", Zheng Li", Ying Zhang", Yuxiao Li, Xueqian Wang, Shuo Wang, Yuerong Gui, Jun Dong, \\ Wei Hou
}

Department of Oncology, Guang'an Men Hospital, China Academy of Chinese Medical Sciences, Beijing, China

Contributions: (I) Conception and design: D Wang, Z Li; (II) Administrative support: W Hou, Y Zhang; (III) Provision of study materials or patients: X Wang; (IV) Collection and assembly of data: Y Li, S Wang; (V) Data analysis and interpretation: Y Gui, J Dong; (VI) Manuscript writing: All authors; (VII) Final approval of manuscript: All authors.

\#These authors contributed equally to this work.

Correspondence to: Wei Hou, MD. Guang'an Men Hospital, China Academy of Chinese Medical Sciences, No. 5 Beixian'ge Street, Xicheng District, Beijing 100053, China. Email: houwei1964@163.com.

\begin{abstract}
Radiotherapy is one of the common means of cancer treatment, especially in the treatment of lung cancer. However, radiation therapy can cause lung tissue radiation lung injury. The study of this disease can reduce its incidence and avoid the occurrence of radiation pulmonary fibrosis. In the past 20 years, the study of radiation-induced lung injury (RILI) has attracted more attention. This paper extracts the main text information of RILI-related literature from WOSCC database from 2001 to 2020, uses Citespace and VOSviewer for visual analysis, and presents the results. We found that in the past 20 years, there have been 4,665 articles on RILI, and the number of articles published reached a peak in 2017. The United States is the main leader in this research field, among which UNIV Texas MD Anderson Cancer Center has published many research results in this field. The most active author is Liao Zhongxing, and the most influential journal is Int $\mathcal{F}$ Radiat Oncol, which provides a platform for scholars in related fields to publish their articles. Current research focuses mainly on randomized controlled trials related to RILI, the relationship between dose-volume histogram analysis and RILI formation, the protection of normal lung tissue, the effect of stereoscopic radiotherapy on RILI and the pathogenesis of RILI. In the study of the formation mechanism of RILI, the main research directions include the apoptosis mechanism of epithelial and endothelial cells, cytokine cascade theory, immune mechanism regulation process, oxidative stress mechanism, etc.
\end{abstract}

Keywords: Radiation-induced lung injury (RILI); bibliometric; visual analysis; CiteSpace; VOSviewer

Submitted Jun 23, 2021. Accepted for publication Sep 07, 2021.

doi: 10.21037/apm-21-1682

View this article at: https://dx.doi.org/10.21037/apm-21-1682

\section{Introduction}

Radiotherapy (RT) is a commonly used means of cancer treatment (1), which can also cause damage to normal human tissues (2). In lung cancer patients receiving radiotherapy, $5-20 \%$ of patients will develop radiationinduced lung injury (RILI) (3). RILI includes radiation pneumonia (RP) and radiation-induced pulmonary fibrosis (RIFI). The RP stage mainly occurs 1-6 months after radiotherapy (4), and pulmonary tissue fibrosis will gradually appear after 6 months (5), with a poor prognosis. The main symptoms of RP are cough, fever, chest pain, fatigue, and dyspnea, which can significantly affect the quality of life of patients and even lead to death (6). Currently, RILI is mainly in the clinical treatment of glucocorticoid hormones, antibiotics, antioxidants, oxygen and other respiratory support treatment (7), symptomatic radiationinduced lung injury (SRILI) is a serious complication of radical radiotherapy (8), but the side effects of hormone therapy are significant, so we need to find a more suitable 


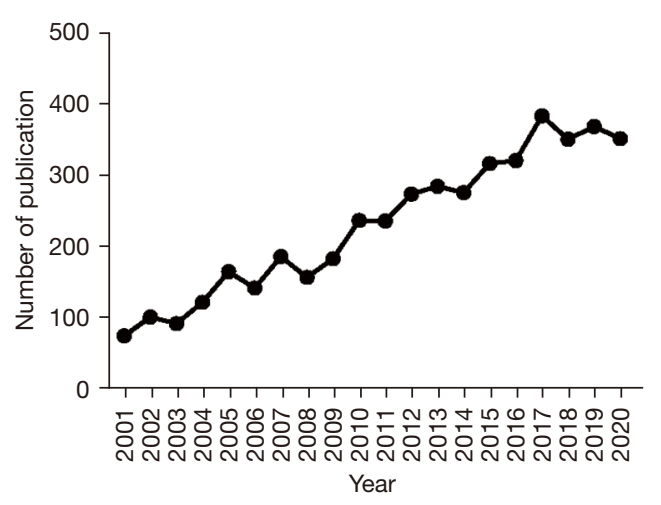

Figure 1 The number of annual publications in RILI research from 2001 to 2020 . RILI, radiation-induced lung injury.

treatment. We urgently need to explore the pathogenesis of RILI and develop new therapeutic strategies to prevent and treat this disease. Both CiteSpace (9) and VOSviewer (10) are information visualization software, which can conduct a quantitative analysis of literature and produce visual maps to show hot topics in the research field. At present, no literature has systematically summarized the research status and hot spots of RILI. Therefore, this paper used CiteSpace and VOSviewer software combined with bibliometrics to statistically analyze the studies related to RILI from 2001 to 2020, providing objective guidance for scholars in this field.

\section{Methods}

\section{Search method}

Data source: Web of Science Core Collection (WOSCC) database, retrieval strategy: TS= ('Radiation-induced lung injury' OR 'RILI' OR 'radioactive lung injury' OR 'RILT' OR 'radio-pulmonary lesion' OR 'Radiation Pneumonitis' OR 'Radiation-induced pulmonary fibrosis' OR 'Radiation pulmonary fibrosis'). Time period: January 2001 to December 2020. Index: SCI-Expand.

\section{Data download}

Exports the full record of the search results (including all authors, titles, source journals, keywords) and references in plain text format in WOSCC. Retrieve and download the data within 1 day (January 2, 2021) to avoid changes due to daily database updates.

\section{Analytical methods}

CitespaceV 5.7.R2 was used to draw the map of national and institutional cooperation, keyword co-occurrence map, literature, and journal co-citation map, and VOSviewer 1.6.15 was used to draw the map of the author cooperation. In the atlas, nodes represent countries, institutions, keywords, cocited literature and journals, and links between nodes usually represent cooperation or co-citation relationships. The colors of the nodes and lines change depending on the year. The CiteSpace software is able to present trends and dynamics across the literature and extract key nodes in the research area.

\section{Results}

\section{General information and annual publications}

A total of 4,665 articles related to RILI were retrieved, with the citation frequency of 107,490 , the average citation frequency of 23.04, and H-index of 128. As shown in Figure 1, the average number of papers related to RILI is 233 per year, and 2017 is the peak year of publication [386], in 2020, 354 papers were published, with the output remaining at a relatively high level.

\section{Active countries and institutions}

The maps of national cooperation (Figure $2 A, \mathrm{~N}=42, \mathrm{E}=47$ ) and institutional cooperation (Figure $2 B, \mathrm{~N}=485, \mathrm{E}=701$ ) were generated using CiteSpace software. Researchers from 485 institutions in 42 countries or territories have published articles on RILI. The Table 1 and Table 2 listed the top 5 countries and institutions that have contributed the most to research in this field. The largest number of publications in this field are in the United States, where UNIV Texas MD Anderson Cancer Center is an authority in this field. The second most published country is China, and Fudan Univ ranks fourth. Countries such as Spain, South Korea, Switzerland, England, and Sweden all have purple rings, proving significant contributions in this field.

\section{Active authors}

We presented the collaborative relationships of the top 100 most active authors in the field and found that there are 13 collaborative teams (Figure 3). Table 3 lists the top 10 most published authors. The two most active authors, 
A

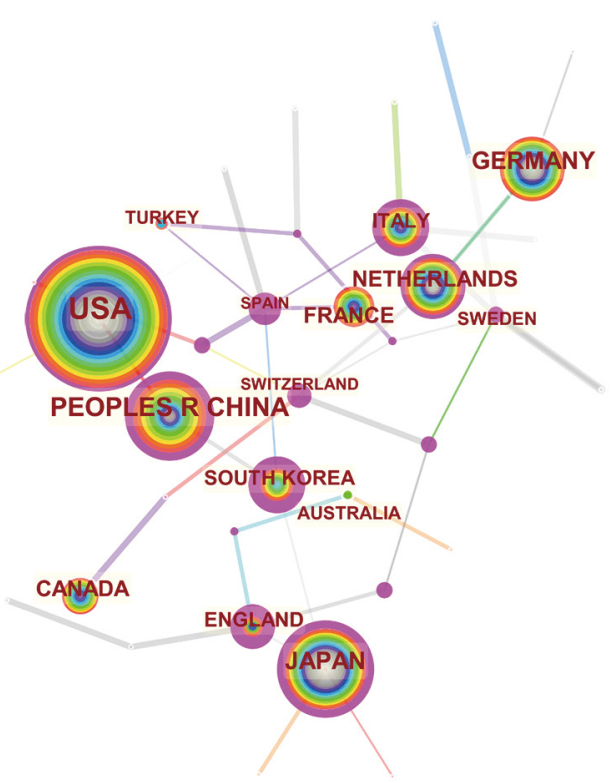

B

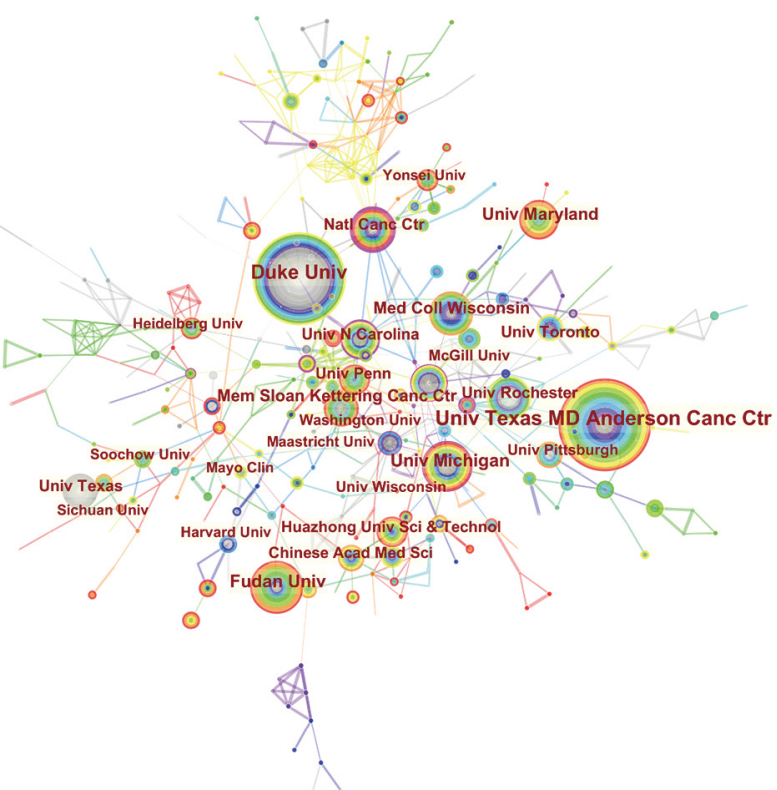

Figure 2 The analysis of active countries and institutions. (A) Network of countries/territories engaged in RILI research; (B) Network of institutions engaged in RILI research. RILI, radiation-induced lung injury.

Table 1 The top 5 countries for centrality and publications in RILI research

\begin{tabular}{lccccc}
\hline Rank & Frequency & Country & Rank & Centrality & Country \\
\hline 1 & 1,281 & USA & 1 & 0.65 & Spain \\
2 & 584 & China & 2 & 0.55 & South Korea \\
3 & 397 & Japan & 3 & 0.5 & Switzerland \\
4 & 271 & Germany & 4 & 5.48 & England \\
5 & 178 & The Netherlands & 5 & 0.38 & Sweden \\
\hline
\end{tabular}

RILI, radiation-induced lung injury.

Table 2 The top 5 institutions for centrality and publications in RILI research

\begin{tabular}{llllll}
\hline Rank & Frequency & Institution & Rank & Centrality & Institution \\
\hline 1 & 120 & Univ Texas MD Anderson Canc Ctr & 1 & 0.45 & Natl Canc Ctr \\
2 & 112 & Duke Univ & 2 & 0.34 & Univ N Carolina \\
3 & 65 & Univ Michigan & 3 & 0.23 & Emory Univ \\
4 & 60 & Fudan Univ & 4 & 0.22 & Univ Calif San Francisco \\
5 & 57 & Univ Maryland & 5 & 0.21 & Vrije Univ Amsterdam \\
\hline
\end{tabular}

RILI, radiation-induced lung injury. 


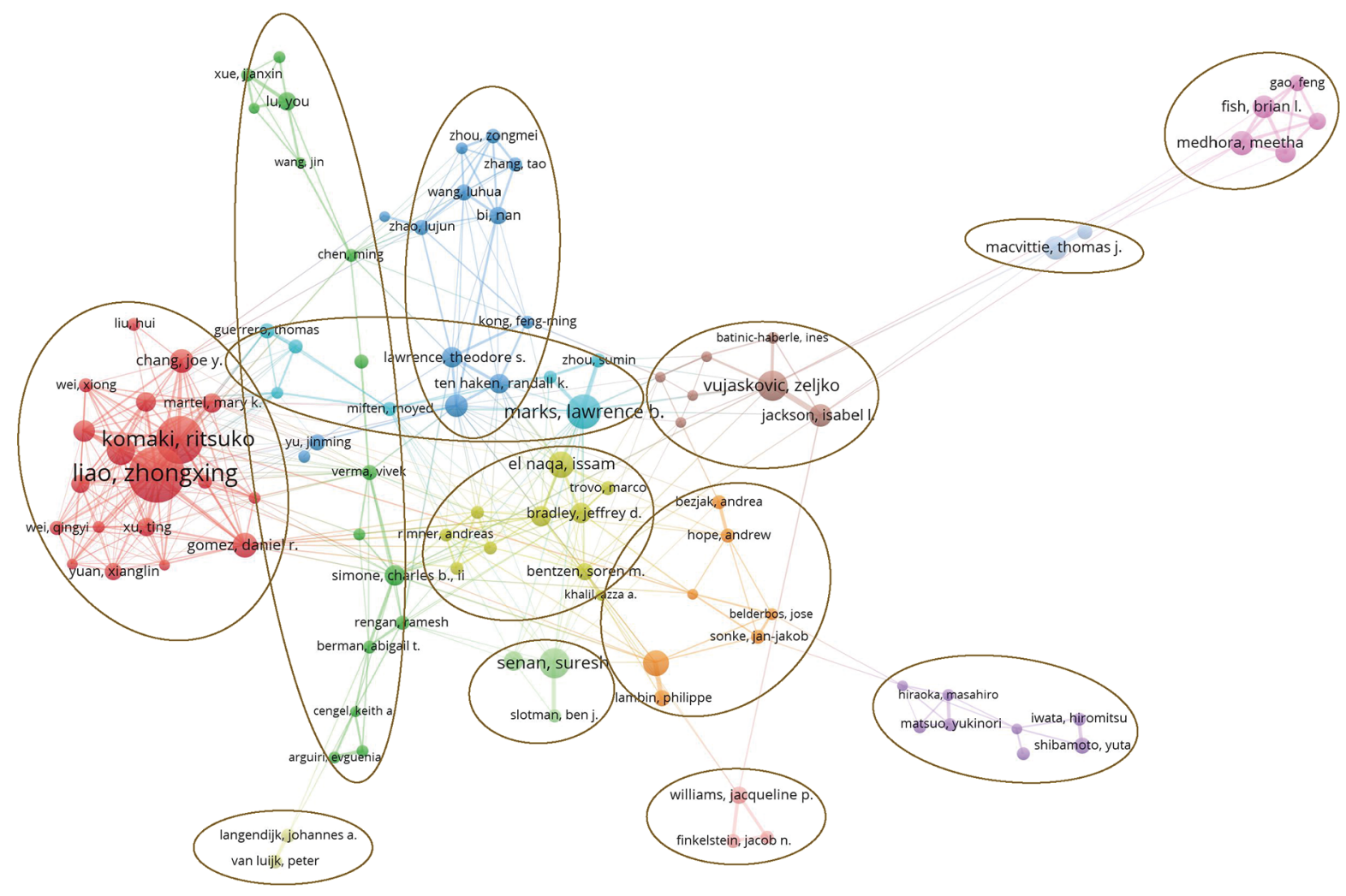

Figure 3 The top 100 active authors in the RILI research: there are 13 clusters. RILI, radiation-induced lung injury.

Table 3 The top 10 authors for publications in RILI research

\begin{tabular}{llc}
\hline Rank & Name & Weight (occurrences) \\
\hline 1 & Liao, Zhong Xing & 74 \\
2 & Komaki, Ritsuko & 61 \\
3 & Marks, Lawrence B. & 40 \\
4 & Vujaskovic, Zeljko & 35 \\
5 & Senan, Suresh & 34 \\
6 & Mohan, Radhe & 31 \\
7 & De Ruysscher, Dirk & 29 \\
8 & El Naqa, Issam & 28 \\
9 & Gomez, Daniel R. & 27 \\
10 & Chang, Joey. & 25 \\
\hline
\end{tabular}

RILI, radiation-induced lung injury.

Liao Zhongxing and Ritsuko Komaki, are both from The Department of Radiation Oncology of The University of Texas MD Anderson Cancer Center. The third author is
Lawrence B. Marks of Duke University Medical Center.

\section{Keyword co-occurrence and burst}

Keyword co-occurrence analysis can display the hot spots of research, and keywords with high frequency are often the main research direction in this field. The top 10 keywords with the highest frequency in 2001-2020 (Figure 4) are radiotherapy [985], pneumonitis [810], radiation pneumonitis [589], therapy [580], irradiation [573], radiation-therapy [564], lung cancer [468], toxicity [453], cancer [444], chemotherapy [419].

Strong citation bursts can reveal hot words at the forefront of research. We've listed top 20 keywords with the strongest citation bursts (Table 4), including randomized trial, volume histogram analysis, stereotactic body radiotherapy, mechanism, risk factors, lung injury, 3-dimensional conformal radiotherapy, activation, growth factor-beta, non-small cell lung cancer, idiopathic pulmonary fibrosis. Among the latest words to appear in the last five years (Table 5) are intensity-modulated radiotherapy, 


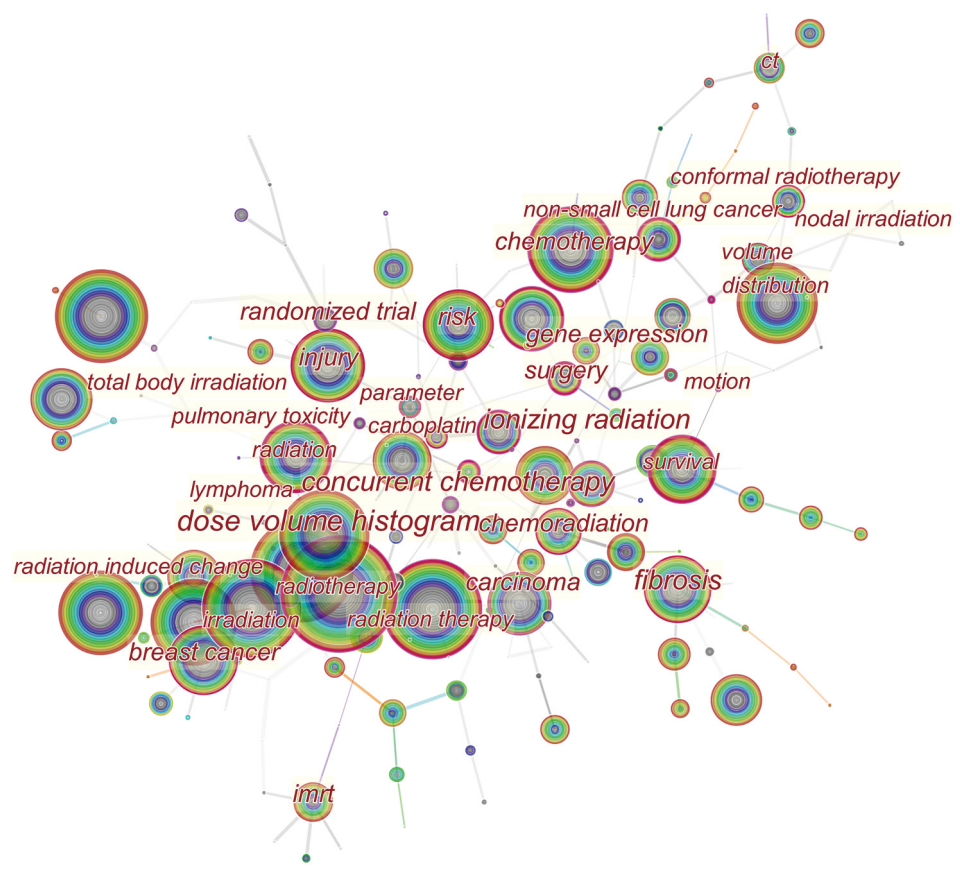

Figure 4 The analysis of keywords in RILI research. RILI, radiation-induced lung injury.

risk factor, damage, activation, cell, impact, pulmonary fibrosis, predictors, etc.

\section{Co-cited journals and references}

Co-citation refers to the phenomenon that two papers are jointly cited by one or more later papers. The circles in the figure reflect the citations of the downloaded journals and references. The more citations, the larger the circles, and the color changes with the year. The top 5 journals (Figure 5 , Table 6) and the top 5 references (Figure 6, Table 7) with the highest citation frequency and the strongest centrality in this field are listed. Int 7 Radiat Oncol ranked highest (2,835, $\mathrm{IF}=5.859)$, followed by Radiother Oncol $(2,004, \mathrm{IF}=4.856)$, and $\mathcal{f}$ Clin Oncol ranked third $(1,725, \mathrm{IF}=32.956)$. Int $\mathcal{f}$ Radiat Oncol and $7 \mathrm{Clin} \mathrm{Oncol}$ are also the two journals with the highest centrality ranking, which proves that these two journals are important in the field of RILI. Robert Timmerman's article published in FAMA in 2010 was the most frequently cited, while Andrew J. Hope's article published in Int 7 Radiat Oncol in 2006 ranked the highest for centrality.

\section{Discussion}

\section{General information}

The number of RILI studies has been increasing year by year, with 4.5 times more published in 2020 than in 2001. Compared with the peak in 2017 , the number of articles in 2020 has decreased but still remains at a high level, proving that although a large number of measures and advanced equipment to reduce the effects of radiation have appeared in recent years, such as volume histogram analysis and stereotactic body radiotherapy, the progress of the disease has not been well controlled in essence. The research on RILI has still attracted great attention from scholars. Combined with the emergent word table, it can be speculated that the publication peaks in 2005, 2007 and 2017 may be associated with volume histogram analysis, 3-dimensional conformal radiotherapy (3D-CRT), Stereotactic body is related to radiotherapy.

Both the United States and China are countries that have published extensively in this field, but the United States has a long research history, while China has published more articles recently and has a short research history in this field. 
Table 4 Top 20 keywords with the strongest citation bursts

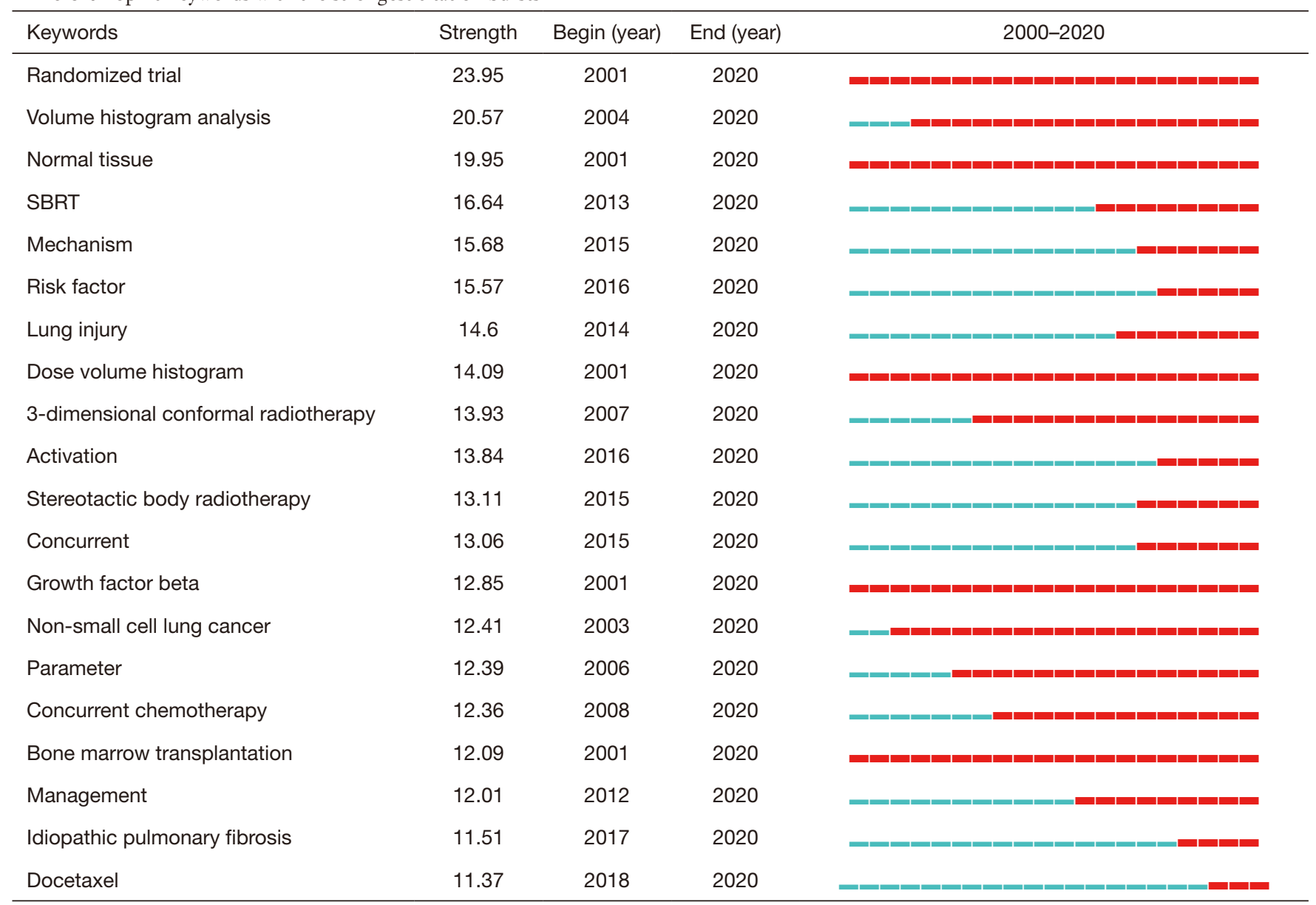

SBRT, stereotactic body radiation therapy.

This may be due to the late introduction of radiotherapy technology. Spain has a high centrality, which means that the country's scholars publish papers that are recognized and cited by a wide range of scholars.

In terms of the number of publications, the authors who contributed the most were Liao Zhongxing and Ritsuko Komaki. The authors' collaborative map shows that they have formed a collaborative group to study predictors of RP and different fibrosis patterns in RILI. Liao Zhongxing's early research was on the formation process of RP (11) and the distribution of its key sites (12), This laid the foundation for subsequent RILI studies on relevant targets. In addition, he found the correlation between transforming growth factor $\beta 1$ (TGF $\beta 1$ ) and RP at the gene level, and proposed that TGF $\beta 1$ could be used as a reliable predictor of RP (13). His findings are supported by recent studies which have also demonstrated that TGF- $\beta 1$ is an important fibrotic growth factor and can be produced by a variety of cell types.

Ritsuko Komaki demonstrated the advantages of 3D-CRT technology, which has been shown to reduce side effects and increase the therapeutic dose to tumors, and may better control tumor progression. Three radiological fibrosis patterns that differ from traditional RILI are introduced to help scholars understand and correctly interpret CT scan results after 3D-CRT (14). These works provide important value for clinical diagnosis and treatment. Lawrence B. Marks, whose work is mainly related to the exploration of the mechanism of RILI formation, demonstrated that the production of reactive oxygen species promotes RILI (3). It can be seen from the cluster diagram of authors' cooperation relationship that there are 13 relatively independent research groups, which may be related to their geographical location and have a certain impact on the academic communication among the 
Table 5 The strongest citation bursts keywords after 2016

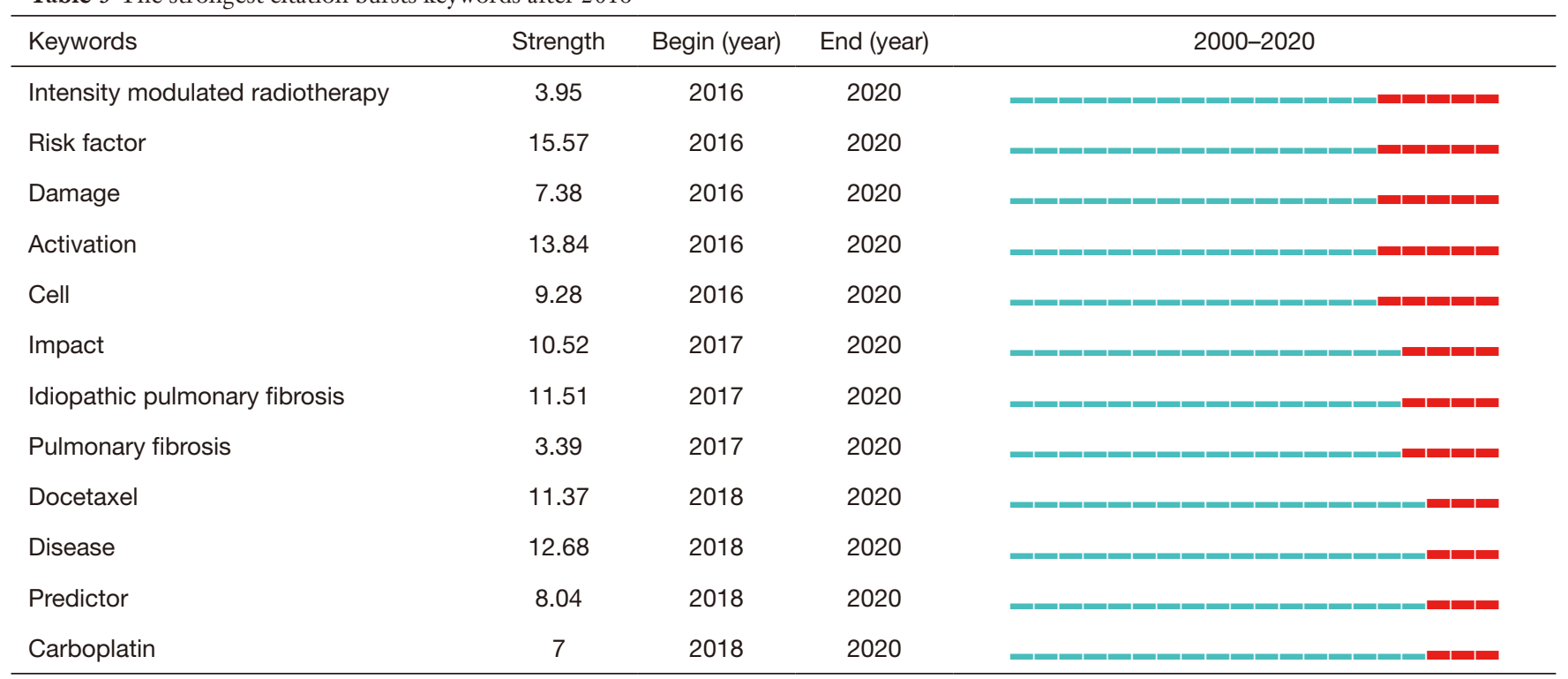

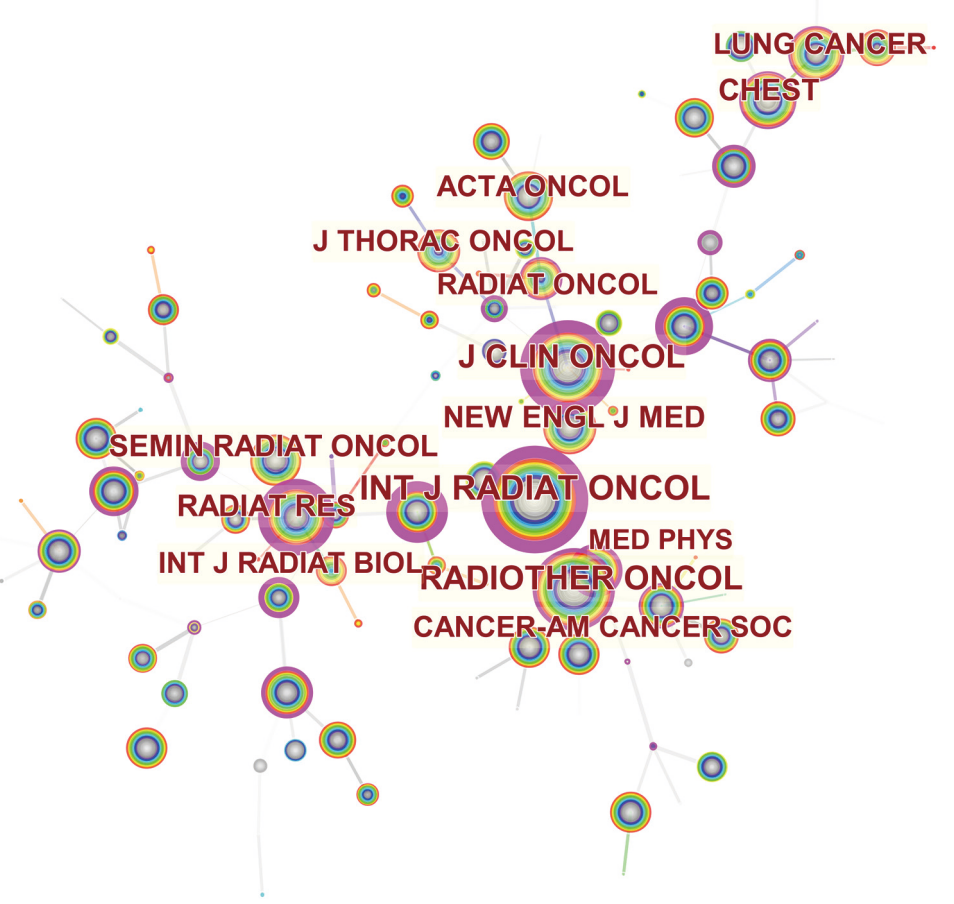

Figure 5 The analysis of co-cited journals: co-citation network of journals from publications in RILI research. RILI, radiation-induced lung injury. 
Table 6 The top 5 co-cited journals in RILI research

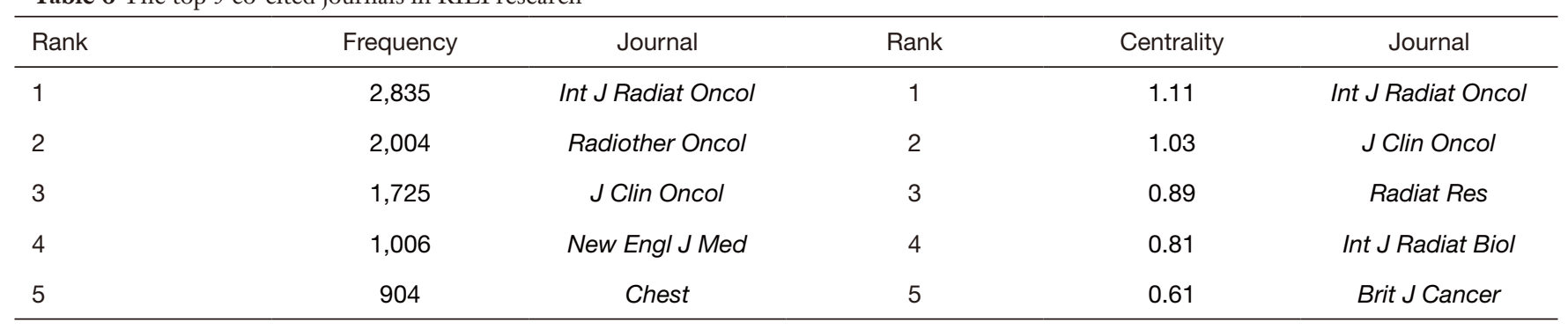

RILI, radiation-induced lung injury.

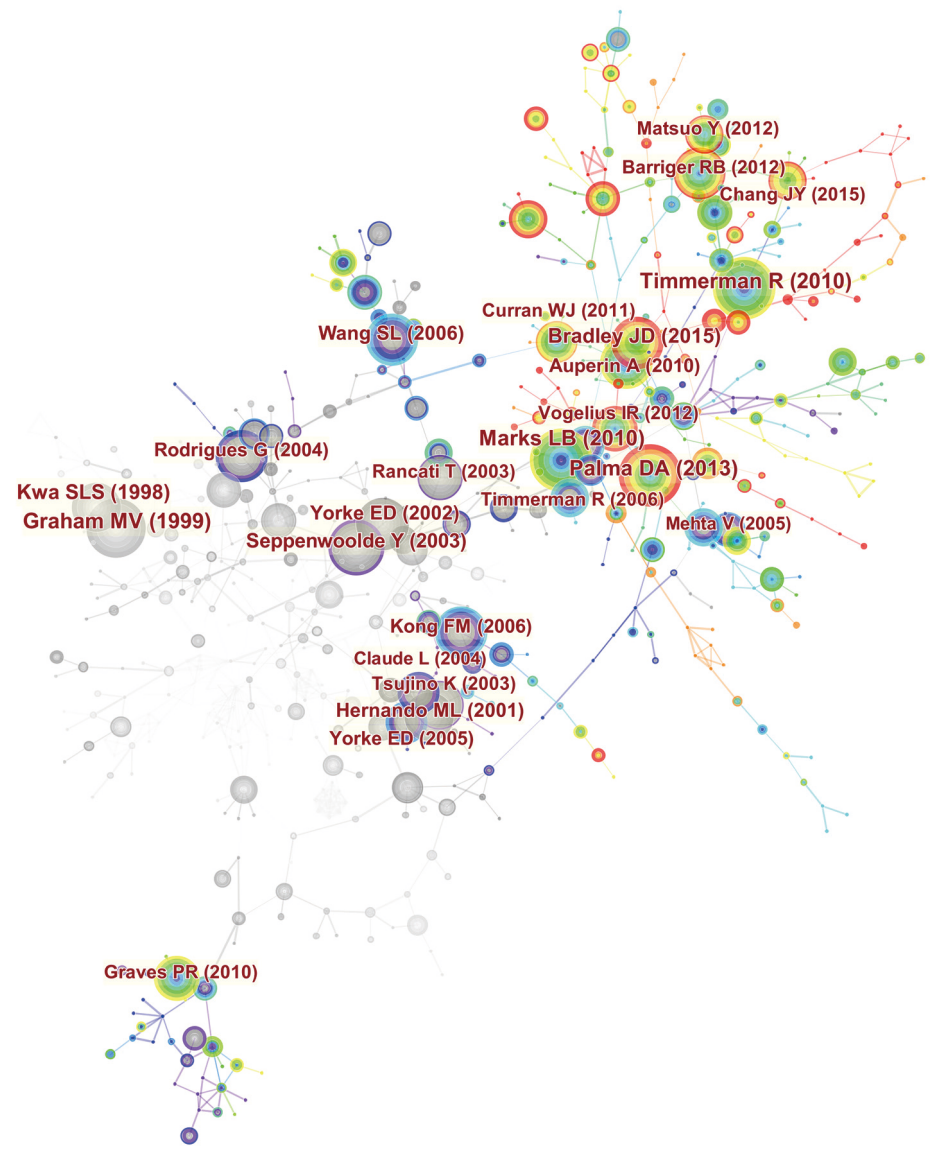

Figure 6 The analysis of co-cited references: co-citation network of references from publications in RILI research. RILI, radiation-induced lung injury.

groups.

\section{Citation information}

Int $\mathcal{F}$ Radiat Oncol is the journal of centralization and the highest number of publications, the publication direction is mainly related to tumor radiation therapy, molecular radiation biology, tumor sensitization and normal tissue protection, dosing and conformal radiation therapy and other research progress, providing the direction for RILI field academic paper publication.

The most frequently cited article was published by 
Table 7 The top 5 co-cited references in RILI research

\begin{tabular}{|c|c|c|c|c|c|}
\hline Rank & Frequency & Reference & Rank & Centrality & Reference \\
\hline 2 & 155 & $\begin{array}{l}\text { Palma DA, 2013, Int J Radiat Oncol, } \\
\text { V85, P444 }\end{array}$ & 2 & 0.43 & $\begin{array}{l}\text { Chang DT, 2006, Int J Radiat Oncol, } \\
\text { V65, P125 }\end{array}$ \\
\hline 3 & 146 & $\begin{array}{l}\text { Graham MV, 1999, Int J Radiat Oncol, } \\
\text { V45, P323 }\end{array}$ & 3 & 0.41 & $\begin{array}{l}\text { Ang KK, 1998, Semin Radiat Oncol, } \\
\text { V8, P230 }\end{array}$ \\
\hline 4 & 143 & $\begin{array}{l}\text { Marks LB, 2010, Int J Radiat Oncol, } \\
\text { V76, P0 }\end{array}$ & 4 & 0.39 & $\begin{array}{l}\text { Yamada M, 1998, Eur J Cancer, } \\
\text { V34, P71 }\end{array}$ \\
\hline 5 & 116 & $\begin{array}{l}\text { Bradley JD, 2015, Lancet Oncol, } \\
\text { V16, P187 }\end{array}$ & 5 & 0.36 & $\begin{array}{l}\text { Robnett TJ, 2000, Int J Radiat Oncol, } \\
\text { V48, P89 }\end{array}$ \\
\hline
\end{tabular}

RILI, radiation-induced lung injury.

Robert Timmerman in $\mathcal{F} A M A$ Journal in 2010 (15), which found that the 3 -year survival rate of inoperable NSCLC patients receiving SBRT was 55.8\%, with a high local tumor control rate and moderate treatment-related morbidity, this provides a basis for the applicability of SBRT. The most centrality article was published by Andrew J. Hope in Int 7 Radiat Oncol in 2006 (16), which evaluated the clinical, dosimetry, and spatial parameters related to RP, and emphasized the importance of lower tumor and dosimetry information in the prediction of RP incidence, which was also confirmed in subsequent studies (17).

\section{Research frontiers}

Based on the keyword co-occurrence atlas and strong citation bursts analysis, the top five hotspots were: (I) randomized controlled trials (RCT) related to radioactive lung injury (23.95); (II) dose-to-volume histogram analysis and the relationship between RILI formation (20.57); (III) protection of normal lung tissue (19.95); (IV) the effectiveness of stereotactic radiotherapy for RILI (16.64); (V) the mechanism of RILI formation (15.68). Randomized controlled trials, protection of normal tissues, and dosevolume histogram analysis have been popular for 20 years. Stereotactic radiotherapy, RILI research mechanism, risk factors, activation pathways and so on have only become new research hotspots in the past five years.

As for the research mechanism of RILI, according to the relevant literature review, scholars could conduct research from the following perspectives: (I) apoptosis mechanism of epithelial and endothelial cells: Celine Almeida found that after receiving radiotherapy, lung tissues will experience vascular wall thickening, inflammatory cell accumulation, collagen deposition, and local fibrosis, etc., and suggested that epithelial-mesenchymal transition (EMT) may play an important role in the development of RIFI (18). Fibroblasts in the alveolar lumen aggregate and secrete angiotensin and hydrogen peroxide to induce apoptosis of alveolar epithelial cells (19). (II) Cytokine cascade theory: at the cellular level, radiation can induce the production of a large number of pro-inflammatory and pro-fibrotic factors (20), which will continue for a long and slow time after the end of radiotherapy. Among them, TGF $\beta 1$ and tumor necrosis factor $\alpha(\mathrm{TNF}-\alpha)$ play a key role, and multiple pathways such as Nrf2-ARE and TGF- $\beta 1 /$ Smad are involved in cytokine initiation. (III) Immune mechanism regulation process: helper $\mathrm{T}$ cell 1/Helper $\mathrm{T}$ cell 2 (Th1/Th2) imbalance plays an important role in the occurrence of $\mathrm{RP}$ and pulmonary fibrosis. In the initial stage of radiation injury, Th1 cells are activated and release IFN- $\gamma$, which is associated with acute inflammatory response (21). (IV) Oxidative stress mechanism: Izumi found that (22) Suplatast Tosilate can reduce pulmonary fibrosis and improve the survival rate after radiation by inhibiting the radiationinduced intracellular ROS and DNA double-strand breaks, down-regulating the levels of oxidative stress markers and cytokines of inflammation and fibrosis in the lungs of irradiated mice. Nuclear factor-erythrocyte 2-related factor 2 (Nrf2) is a key transcriptional regulator of the antioxidant cascade (23) and has been shown to modulate life span in mice after chest irradiation (24).

Therefore, through the regulation of EMT process, TGF- $\beta 1 /$ Smad pathway, Th1/Th2 balance, Nrf2 and other key transcription regulatory factors related to 
antioxidant cascade reaction, as well as the exploration of RILI related predictors, we can explore and verify the mechanism of action of different drugs and further explain the pathogenesis of RILI. It is of great significance for the research and development of new drugs, the prevention of RILI and the improvement of radiotherapy effect, and is a hot research direction of scholars at present.

The literature source in this study was WOSCC database, and the literature retrieval only included English literature. Follow-up research could also include other medical literature databases for more comprehensive research. This study used CitespaceV and VOSviewer software to make a visual analysis of the included literature, which can only provide scholars with some possible research hotspots. In the future, more in-depth literature retrieval and more rigorous scientific research on hot topics are needed.

\section{Conclusions}

This study summarizes the research status of RILI in the past 20 years. RILI's research publications are increasing year by year, and cooperation between countries and institutions is not close enough. This study provides help for scholars to find partners and important literature in this field, provides direction for publishing journals, and guides identifying research hotspots in this field.

\section{Acknowledgments}

Funding: This work was supported by the National Natural Science Foundation of China [No. 8207142125].

\section{Footnote}

Conflicts of Interest: All authors have completed the ICMJE uniform disclosure form (available at https://dx.doi. org/10.21037/apm-21-1682). The authors have no conflicts of interest to declare.

Ethical Statement: The authors are accountable for all aspects of the work in ensuring that questions related to the accuracy or integrity of any part of the work are appropriately investigated and resolved. All information is supplementary and does not contain any personal information, therefore informed consent was not required. Open Access Statement: This is an Open Access article distributed in accordance with the Creative Commons
Attribution-NonCommercial-NoDerivs 4.0 International License (CC BY-NC-ND 4.0), which permits the noncommercial replication and distribution of the article with the strict proviso that no changes or edits are made and the original work is properly cited (including links to both the formal publication through the relevant DOI and the license). See: https://creativecommons.org/licenses/by-nc-nd/4.0/.

\section{References}

1. Belderbos J, Sonke JJ. State-of-the-art lung cancer radiation therapy. Expert Rev Anticancer Ther 2009;9:1353-63.

2. Park KJ, Chung JY, Chun MS, et al. Radiation-induced lung disease and the impact of radiation methods on imaging features. Radiographics 2000;20:83-98.

3. Marks LB, Yu X, Vujaskovic Z, et al. Radiation-induced lung injury. Semin Radiat Oncol 2003;13:333-45.

4. Blom Goldman U, Wennberg B, Svane G, et al. Reduction of radiation pneumonitis by $\mathrm{V} 20$-constraints in breast cancer. Radiat Oncol 2010;5:99.

5. Lind P. Clinical relevance of pulmonary toxicity in adjuvant breast cancer irradiation. Acta Oncol 2006;45:13-5.

6. Ohe Y. Treatment-related death from chemotherapy and thoracic radiotherapy for advanced cancer. Panminerva Med 2002;44:205-12.

7. Kainthola A, Haritwal T, Tiwari M, et al. Immunological Aspect of Radiation-Induced Pneumonitis, Current Treatment Strategies, and Future Prospects. Front Immunol 2017;8:506.

8. Vujaskovic Z, Marks LB, Anscher MS. The physical parameters and molecular events associated with radiation-induced lung toxicity. Semin Radiat Oncol 2000;10:296-307.

9. Chen C. CiteSpace II: Detecting and visualizing emerging trends and transient patterns in scientific literature. J Am Soc Inf Sci Technol 2006;57:359-77.

10. van Eck NJ, Waltman L. Software survey: VOSviewer, a computer program for bibliometric mapping. Scientometrics 2010;84:523-38.

11. Liao ZX, Travis EL, Tucker SL. Damage and morbidity from pneumonitis after irradiation of partial volumes of mouse lung. Int J Radiat Oncol Biol Phys 1995;32:1359-70.

12. Tucker SL, Liao ZX, Travis EL. Estimation of the spatial distribution of target cells for radiation pneumonitis in mouse lung. Int J Radiat Oncol Biol 
Phys 1997;38:1055-66.

13. Yuan X, Liao Z, Liu Z, et al. Single nucleotide polymorphism at rs1982073:T869C of the TGFbeta 1 gene is associated with the risk of radiation pneumonitis in patients with non-small-cell lung cancer treated with definitive radiotherapy. J Clin Oncol 2009;27:3370-8.

14. Koenig TR, Munden RF, Erasmus JJ, et al. Radiation injury of the lung after three-dimensional conformal radiation therapy. AJR Am J Roentgenol 2002;178:1383-8.

15. Timmerman R, Paulus R, Galvin J, et al. Stereotactic body radiation therapy for inoperable early stage lung cancer. JAMA 2010;303:1070-6.

16. Hope AJ, Lindsay PE, El Naqa I, et al. Modeling radiation pneumonitis risk with clinical, dosimetric, and spatial parameters. Int J Radiat Oncol Biol Phys 2006;65:112-24.

17. Huang MJ, Jiang Y, Liu WP, et al. Early or up-front radiotherapy improved survival of localized extranodal NK/ T-cell lymphoma, nasal-type in the upper aerodigestive tract. Int J Radiat Oncol Biol Phys 2008;70:166-74.

18. Almeida C, Nagarajan D, Tian J, et al. The role of alveolar epithelium in radiation-induced lung injury. PLoS One 2013;8:e53628.

19. King TE Jr, Pardo A, Selman M. Idiopathic pulmonary fibrosis. Lancet 2011;378:1949-61.

20. Schaue D, Micewicz ED, Ratikan JA, et al. Radiation and inflammation. Semin Radiat Oncol 2015;25:4-10.

21. Chiang CS, Liu WC, Jung SM, et al. Compartmental responses after thoracic irradiation of mice: strain differences. Int J Radiat Oncol Biol Phys 2005;62:862-71.

22. Izumi Y, Nakashima T, Masuda T, et al. Suplatast tosilate reduces radiation-induced lung injury in mice through suppression of oxidative stress. Free Radic Biol Med 2019;136:52-9.

23. Ishii T, Itoh $\mathrm{K}$, Takahashi $\mathrm{S}$, et al. Transcription factor Nrf2 coordinately regulates a group of oxidative stress-inducible genes in macrophages. J Biol Chem 2000;275:16023-9.

24. Travis EL, Rachakonda G, Zhou X, et al. NRF2 deficiency reduces life span of mice administered thoracic irradiation. Free Radic Biol Med 2011;51:1175-83.
Cite this article as: Wang D, Li Z, Zhang Y, Li Y, Wang X, Wang S, Gui Y, Dong J, Hou W. Bibliometric analysis of research relating to radiation-induced lung injury [2001-2020]. Ann Palliat Med 2021;10(10):11166-11176. doi: 10.21037/apm21-1682 